\title{
Research and implementation of innovative technologies for the use of composite polymer materials to protect the root systems of seedlings from desiccation and increase their establishment
}

\author{
V.V. Kopytkov ${ }^{1, *}, C h$. Dorzhsuren ${ }^{2}$, and Yu.A. Tairbergenov ${ }^{3}$ \\ ${ }^{1} \mathrm{SSU}$ "Forest Institute of the National Academy of Sciences of Belarus", Gomel, Republic of Belarus \\ ${ }^{2}$ Botanical Garden-Institute of the Academy of Sciences of Mongolia, city of Ulaanbaatar, Mongolia \\ ${ }^{3}$ Kazakh Agrotechnical University n.a. S. Seifullin, Nur-Sultan, Republic of Kazakhstan
}

\begin{abstract}
In the presented materials, the physicochemical properties of composite polymer materials for protecting the root systems of forest seedlings from desiccation are studied. The conducted studies on the production of composite polymer materials allowed to establish their optimal ratios: the sodium salt carboxymethyl cellulose from 4 active substance wt.\%, as target additives contains potassium chloride from 6.0 to $9.0 \mathrm{wt} . \%$ and ammonium nitrate from 0.004 to $0.006 \mathrm{wt} . \%$. This ratio of target additives corresponds to the optimal relative viscosity of the composite polymer material equal to $170-175 \mathrm{~s}$. Treatment of the root systems of seedlings with a composite polymer material allows not only to prevent desiccation, increase their establishment on the planting area, but also to reduce mechanical damage during transportation and forest planting.
\end{abstract}

\section{Introduction}

Modern achievements in chemistry make it possible to effectively use the developed composite polymer materials in forest planting $[1,2]$.

To preserve moisture in the root zone of the planting material in order to increase the establishment and preservation of forest crops, it is necessary to study the influence of all components of the composite polymer material and determine their optimal value for obtaining the maximum silvicultural effect [3-5].

The purpose of the research is the development and research of composite polymer materials to increase the plant establishment. For this purpose, we have investigated the following issues: the development of composite polymer materials and the study of their physical and chemical properties; the study of the influence of composite polymer materials for the establishment of forest crops; the practical use of the developed composite polymer materials during forest planting.

* Corresponding author: kopvo@mail.ru 


\section{Materials and methods of research}

The objects of the study were aqueous solutions of a water-soluble polymer with target additives. Research on the development and production of composite polymer materials was carried out in the Institute of Mechanics of Metal-Polymer Systems named after V.A. The National Academy of Sciences of Belarus (IMMS NASB). The study of the effect of preparations on silvicultural efficiency was carried out in two experimental forestry enterprises of Belarus. Method for determination of flexural resistance on the ShG-1 flexibility scale. The coating tensile stress at break was determined according to GOST 14236-81 "Polymer films. Tensile test method" on a ZM-40 breaking machine manufactured in Germany [6,7].

\section{Research results}

The obtained data of laboratory and field studies were processed by the mathematical statistics method [8].

The study of the preparation effect on silvicultural efficiency was carried out in two experimental forestry enterprises of Belarus, the Osipovichi experimental Forestry Enterprise of the Mogilev State Forestry Production Association and the Mozyr Experimental Forestry Enterprise of the Gomel State Forestry Production Association. Seedlings of Scots pine from these experimental forestry enterprises were selected for laboratory studies (Table 1).

Table 1. Biometric indicators of Scots pine yearlings.

\begin{tabular}{|l|c|c|}
\hline \multirow{2}{*}{\multicolumn{1}{c|}{\multirow{2}{*}{$\begin{array}{c}\text { Indicators } \\
\text { of seedlings }\end{array}$}}} & \multicolumn{2}{|c|}{ Average indicators of seedlings } \\
\cline { 2 - 3 } & Osipovichi & Mozyr \\
\cline { 2 - 3 } & average & average \\
\hline Top length, cm & $9.4 \pm 0.50$ & $9.0 \pm 0.33$ \\
\hline Root collar diameter, mm & $1.9 \pm 1.19$ & $1.3 \pm 0.07$ \\
\hline Root system length, cm & $10.1 \pm 1.0$ & $8.2 \pm 0.53$ \\
\hline
\end{tabular}

Studies on the preparation of the composite polymer material were carried out in the laboratory using a water-soluble polymer $(\mathrm{NaCMC})$ and target additives (potassium chloride and ammonium nitrate). The obtained research results are presented in Table 2.

Table 2. Effect of target additives on the time to complete dissolution and internal stress.

\begin{tabular}{|l|c|c|c|}
\hline \multirow{2}{*}{ Polymer and target additives } & \multicolumn{3}{|c|}{ Content of target additives, wt.\% } \\
\cline { 2 - 4 } & \multicolumn{3}{|c|}{ Experiment options } \\
\cline { 2 - 4 } & I & II & III \\
\hline 1. Na-carboxymethyl cellulose & 4 & 5 & 6 \\
\hline 2. Potassium chloride & 6 & 8 & 0.006 \\
\hline 3. Ammonium nitrate & 0.004 & 0.005 & 54.994 \\
\hline 4. Water & 89.96 & 85.995 & 56 \\
\hline $\begin{array}{l}\text { 1. Time to complete dissolution } \\
\text { of the coating, min }\end{array}$ & 53 & 56 & 0.18 \\
\hline $\begin{array}{l}\text { 2. Internal stresses in coatings, } \\
\text { MPa }\end{array}$ & 0.16 & 0.17 & \\
\hline
\end{tabular}

As can be seen from Table 2, the combination of the selected components allowed to increase the time to complete dissolution of the coating by $6-11 \%$ and reduce internal stresses in the coatings by $6-19 \%$.

The selected concentration of the water-soluble polymer (4-6 wt.\%) allows to obtain a viscous preparation, which can form solid and durable coatings on the plant root systems. 
The introduction of targeted additives in optimal concentrations significantly reduces the physical and chemical properties of composite polymer materials.

We have developed an optimal polymer composition for protecting the root system of coniferous seedlings consisting of NaCMC5 wt.\%, potassium chloride $8.0 \mathrm{wt} . \%$ and ammonium nitrate from $0.005 \mathrm{wt} . \%$. This ratio of target additives is optimal and corresponds to the best relative viscosity of the composite material equal to $170-175 \mathrm{~s}$. This polymer composition was used to study the moisture loss by the root system of coniferous seedlings.

Moisture loss is affected not only by the treatment of root systems, but also by the type of planting material. The greatest water loss by root systems is observed in European larch, the smallest - in Scots pine. This is due to the water consumption rate by seedlings. Moisture loss by root systems occurs intensively in the first 6-8 hours. The amount of water during this time in the root systems decreases by 7-10 times. In the future, the decrease becomes smooth and in two days the amount of moisture in the root systems of coniferous seedlings decreases by 1.2-1.6 times.

Table 3 presents the obtained results of comparing the silvicultural efficiency of the studied preparations.

Table 3. Silvicultural indicators of forest crops of the studied preparations.

\begin{tabular}{|l|l|l|}
\hline \multirow{2}{*}{ Studied indicators } & \multicolumn{2}{|l|}{ Composite preparations } \\
\cline { 2 - 3 } & Domestic & English \\
\hline Establishment of forest crops, \% & 92.3 & 84.1 \\
\hline Preservation of forest crops & 86.5 & 72.4 \\
\hline Possibility of processing in batches & + & - \\
\hline The cost of the preparation, USD & 1.2 & 2.8 \\
\hline
\end{tabular}

The analysis of the data in Table 3 shows that when treating root systems with a developed domestic composite polymer material, the plant establishment increased by $10 \%$, and the forest preservation - by $12 \%$. The developed composite polymer material contains ingredients that perform not only the role of protection against damage and desiccation of root systems, but also are sources of nutrients necessary for the plant growth and development.

As a result of the conducted research, it was found that the developed domestic composite polymer material is more expensive and the amount necessary for the treatment of root systems is greater than in the English preparation.

The effect of treatment of the root systems of coniferous seedlings with composite polymer material on the value of the breaking stress was studied (Table 4).

Table 4. Effect of the diameter of the root system of coniferous seedlings on strength indicators, Mpa.

\begin{tabular}{|l|l|l|l|}
\hline \multirow{2}{*}{$\begin{array}{l}\text { Composition for covering the } \\
\text { root systems of seedlings }\end{array}$} & \multicolumn{3}{|l|}{ Diameter of root systems, mm } \\
\cline { 2 - 4 } & less than 1 & $1-2$ & $\begin{array}{l}\text { more than } \\
2\end{array}$ \\
\hline Pine seedlings & 0.8 & 2.2 & 8.3 \\
\hline Untreated roots & 1.5 & 3.5 & 10.0 \\
\hline Treated roots & 1.0 & 2.5 & 10.1 \\
\hline Larch seedlings
\end{tabular}




\begin{tabular}{|l|l|l|l|}
\hline Treated roots & 1.9 & 4.7 & 14.2 \\
\hline Spruce seedlings & 0.9 & 2.3 & 8.5 \\
\hline Untreated roots & 1.7 & 3.8 & 11.4 \\
\hline Treated roots & & & \\
\hline
\end{tabular}

As can be seen from this table, composite polymer materials contribute to an increase in the strength indicators of the root systems of seedlings. Depending on the diameter of the root systems, the strength indicators change. With the increase in the diameter of the root systems of coniferous seedlings, strength indicators increase. In control seedlings (untreated) with a root diameter of less than $1 \mathrm{~mm}$, the breaking stress for seedlings of Scots pine is $0.8 \mathrm{MPa}$. Roots with a diameter of less than $1 \mathrm{~mm}$ predominate in the weight (up to $80 \%$ of the total weight) above the others.

To implement scientific development, we have completed the technological regulations for obtaining at the Korenevskaya Experimental Forest Base of the National Academy of Sciences of Belarus. At this experimental forest base, the production of concentrated composite polymer material is carried out in an annual volume of 20-25 thousand liters for almost all forestry enterprises of Belarus. In 2021, an order was received from the MF RB for the supply of more than 30 thousand liters of concentrated composite polymer material.

In Kazakhstan and Mongolia, experimental facilities have been laid for the effect of composite polymer material to protect the root systems of planting material and the silvicultural efficiency of their use has been established. In 2014, laboratories for the development of composite polymer material "Tamyrkush" were created and successfully operate in the Kazalinsky Forest Nursery and in the Semey Ormany Reserve. In Mongolia, a laboratory for the development of composite polymer material is being organized on the basis of the Botanical Garden-Institute of the Academy of Sciences of Mongolia.

\section{Conclusions}

The conducted studies on the production of composite polymer materials allowed to establish their optimal ratios: the sodium salt carboxymethyl cellulose from 4 active substance wt.\% of potassium from 6.0 to $9.0 \mathrm{wt} . \%$ and ammonium nitrate from 0.004 to $0.006 \mathrm{wt} . \%$. This ratio of target additives corresponds to the optimal relative viscosity of the composite polymer material equal to $170-175 \mathrm{~s}$.

Treatment of the root systems of seedlings with a composite polymer material allows not only to prevent desiccation, but also to increase the establishment and preservation of forest crops.

\section{Acknowledgements}

The research was carried out with the financial support of the Belarusian Republican Foundation for Fundamental Research within the framework of an International Scientific Project under contract No. B20MN-001.

\section{References}

1. V.V. Kopytkov, Composite polymer materials in forest cultivation, 304 (Mn.: RUP "Pub. house "Belarusian Science", 2008) 
2. A.R. Rodin, V.V. Kopytkov, L.V. Rudakovskaya [et al.], Methodological recommendations for the use of composite materials in forest cultivation, 21 (M., 1991)

3. A.R. Rodin, N.Ya. Popova, E.V. Kandyba, Forestry 1, 28-30 (1997)

4. V.V. Kopytkov, V.S. Kaverin, A.V. Borovkov, V.Vl. Kopytkov, Yu.A. Tairbergenov, New composite polymer compounds for forest cultivation in natural and climatic conditions of Belarus and Kazakhstan, 509 (Mn.: RUP "Pub. house "Belarusian Science", 2014)

5. E.G. Paramonov, M.E. Ananyev, S.N. Zykovich, Bulletin of the Altai Agrarian University 8 (106), 48-50 (2013)

6. GOST 8420-74 Methods for determining the relative viscosity, 6 .

7. I.M. Lipatova [et al.], Textile Chemistry 2, 26-29 (1997)

8. G.N. Zaitsev, Mathematical statistics in experimental botany, 424 (M.: Nauka, 1984) 